Rakenteiden Mekaniikka (Journal of Structural Mechanics)

Vol. 50, No 3, 2017, pp. 333 - 336

https://rakenteidenmekaniikka.journal.fi/index

https://doi.org/10.23998/rm.65096

(c) The author(s) 2017.

Open access under CC BY-SA 4.0 license.

\title{
A new paradigm for fatigue analysis - evolution equation based continuum approach
}

\author{
Joonas Jussila, Sami Holopainen, Terhi Kaarakka, Reijo Kouhia ${ }^{1}$, Jari Mäkinen, \\ Heikki Orelma, Niels Saabye Ottosen, Matti Ristinmaa, and Timo Saksala
}

Summary. A very general continuum based approach to model both low- and high cycle fatigue behaviour is described. The approach allows for both isotropic and anisotropic properties under very general random multiaxial loading histories.

Key words: high-cycle fatigue, low-cycle-fatigue, endurance surface, out-of-phase loading, multiaxial stress state, stochastic loading, gradient effects

Received 28 June 2017. Accepted 18 August 2017. Published online 21 August $201 \%$.

\section{Introduction}

In mechanical engineering design when dimensioning products, fatigue is often the most critical issue. Fatigue of materials under variable loads is a complicated physical process which is characterized by nucleation, coalescence and stable growth of cracks. Nucleation of cracks starts from stress concentrations near persistent slip bands, grain interfaces and inclusions $[1,12,16,17]$. Depending on the intensity of loading two ranges of fatigue lives are identified, namely the low- and high-cycle regime, abbreviated as LCF and $\mathrm{HCF}$, respectively. However, in recent years, it has been observed that fatigue failures can also occur at very high fatigue lives $10^{9}-10^{10}$, below the previously assumed fatigue limits for infinite life. The key difference between LCF and HCF behaviour is that in high-cycle fatigue the macroscopic behaviour of the material is primarily elastic, while in the lowcycle fatigue regime considerable macroscopic plastic deformations take place. This fact can be effectively utilized in the analysis. Transition between low- and high-cycle fatigue for metallic materials occurs between $10^{3}-10^{4}$ cycles.

This paper describes in general terms a unifield approach to model both low- and highcycle fatigue. The high-cycle fatigue part of the model is based on the concept of a moving endurance surface in the stress space with an associated evolving scalar damage variable. In this concept, originally proposed by Ottosen et al. [13] the movement of the endurance surface, as a function of the stress history, is tracked by an evolving back stress type of stress tensor. Therefore this model avoids the ambiguous cycle-counting techniques. This

\footnotetext{
${ }^{1}$ Corresponding author. reijo.kouhia@tut.fi
} 


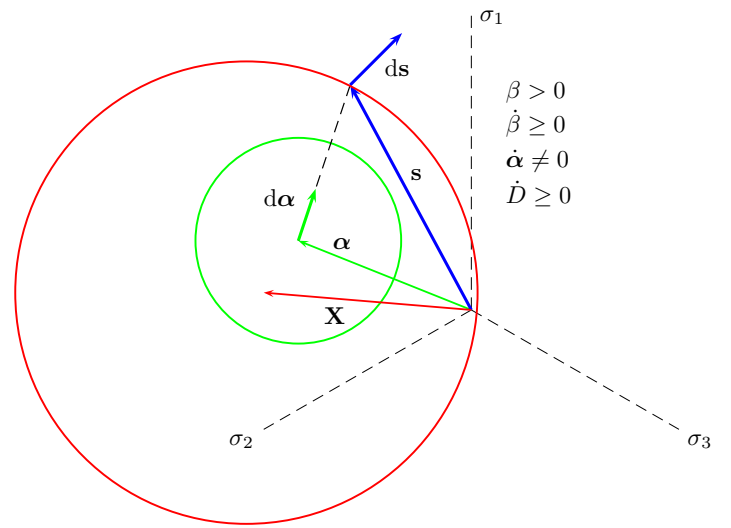

(a)

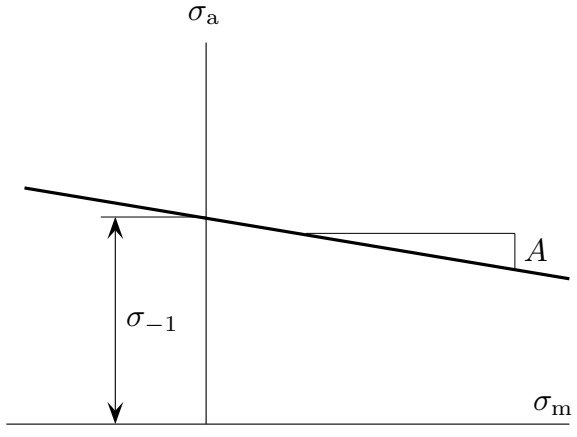

(b)

Figure 1. (a) Endurance surface (green line) inside the yield surface (red line), shown here in the deviatoric plane, moves in the stress space and fatigue damage increases when the stress increment is pointing away from the endurance surface. (b) Haigh-diagram.

approach allows consistent generalisation to anisotropic cases. A transversally isotropic version of this model was developed by Holopainen et al.[3] and an initial approach to model both LCF- and HCF-regimes is decribed in $[10,5]$, also polymer fatigue has been investigated [4].

One of the key deficiences of most fatigue models is that under complex load histories, cycle-counting methods need to be applied. These methods require definition of a representative uniaxial cycle from which a cumulative damage theory is applied to evaluate the accumulated damage. For complex load histories and general stress states these kind of aproaches become increasingly speculative. Reviews and comparisons of different high-cycle fatigue models can be found in studies by [15], [2], [9], and [11].

\section{Basic principle}

Three key ingredients of the evolution equation based fatigue model are introduced: (i) the existence of an endurance surface, (ii) evolution equations for its movement and (iii) damage accumulation. The endurance surface $\beta$ is defined in the stress space

$$
\beta(\boldsymbol{\sigma},\{\boldsymbol{\alpha}\} ; \text { parameters })=0,
$$

where $\boldsymbol{\sigma}$ is the stress tensor and $\{\boldsymbol{\alpha}\}$ denotes the set of internal variables. Evolution of the internal variables and the damage $D$ are described by the rate equations

$$
\{\dot{\alpha}\}=\{\boldsymbol{G}\}(\boldsymbol{\sigma},\{\boldsymbol{\alpha}\}) \dot{\beta}, \quad \text { and } \quad \dot{D}=g\left(\beta, D, \boldsymbol{\varepsilon}^{\mathrm{p}}\right) \dot{\beta} .
$$

In high-cycle fatigue there is no macroscopic plastic straining, thus $\varepsilon^{\mathrm{p}}$ vanish. The form of the functions $\boldsymbol{G}$ and $g$ are important for modelling the finite life durability, while the endurance surface mainly dictates the infinite life resistance. In contrast to plasticity the stress state can lie outside the endurance surface and the evolution of the internal variables and the damage take place only when $\beta \geq 0$ and $\dot{\beta}>0$. The idea of the moving endurance surface is depicted in Fig. 1a in the deviatoric plane.

In the high-cycle fatigue regime, material damage is highly localized and its effect to the macroscopic structural response can be neglected. This fact uncouples the "fictitious" 
fatigue damage from the structural constitutive equations, thus facilitating HCF-analysis as a post-processing from the structural analysis data. This is also true in the LCF/HCF regime, if we assume that the "fatigue damage" does not couple to the constitutive equation. In this case the post-prosessing, however, requires evaluation of elasto-plastic response. In addition, the plastic region should be small as compared to the measures of the analysed structure, to justify the fatigue post-prosessing.

For the endurance surface, the simplest form for isotropic HCF-modelling can be written as

$$
\beta\left(\boldsymbol{\sigma}, \boldsymbol{\alpha} ; A, \sigma_{-1}\right)=\frac{1}{\sigma_{-1}}\left(\bar{\sigma}_{\mathrm{eff}}+A I_{1}-\sigma_{-1}\right)
$$

where $\sigma_{-1}$ is the fatigue strength for fully reversed uniaxial normal stress loading $(R=$ $-1), \bar{\sigma}_{\text {eff }}=\sqrt{3 \bar{J}_{2}}$ is the reduced effective stress, $I_{1}=\operatorname{tr} \sigma$ the first invariant of the stress tensor and $A$ is a constant. The second deviatoric invariant is defined as $\bar{J}_{2}=$ $\frac{1}{2} \operatorname{tr}\left[(\boldsymbol{s}-\boldsymbol{\alpha})^{2}\right]$, where $\boldsymbol{s}=\boldsymbol{\sigma}-\frac{1}{3} I_{1} \boldsymbol{I}$ is the deviatoric stress tensor. This form results for uniaxial cyclic loading in a linear relationship between the mean stress and the fatigue strength amplitude, see Fig. 1 b and Section 4 in [13] for a detailed analysis. In addition, it allows for closed form expressions for the parameters appearing in the endurance surface as a function of experimental fatigue strengths.

For anisotropic fatigue the effective stress depend on the structural tensors describing the anisotropy. Transverse isotropic HCF model is described in [3] and extension to orthotropic symmetry in [6]. It has been successfuly utilized in the design of a telescopic boom structure [7].

\section{Concluding remarks}

An evolution equation based fatigue modelling concept which can be used under general multiaxial irregular stress histories and is amenable to consistent extension to anisotropy, unification of low-cycle and high-cycle regimes and is ideally suited for stochastic analysis [8] is briefly presented. In addition, the size effect influenced by stress gradients can also be included in this model [14].

Acknowledgements. This work was supported in part by Tekes - the National Technology Agancy of Finland projects SCarFace, decision number 40205/12 and MaNuMiES, decision number 3361/31/2015.

\section{References}

[1] V.V. Bolotin. Mechanics of Fatigue. CRC Mechanical Engineering Series. CRC Press, Boca Raton, 1999.

[2] X. Ding, G. He, C. Chen, Z. Zhu, X. Liu, and P.N. Crepeau. A brief review of multiaxial high-cycle fatigue. Metallurgical and Materials Transactions B, 38B:591-599, August 2007. https://doi.org/10.1007/s11663-007-9021-x.

[3] S. Holopainen, R. Kouhia, and T. Saksala. Continuum approach for modeling transversely isotropic high-cycle fatigue. European Journal of Mechanics A/Solids, 60:183-195, 2016. https://doi.org/10.1016/j.euromechsol.2016.06.007.

[4] S. Holopainen, T. Barriere, G. Cheng, and R. Kouhia. Continuum approach for modeling fatigue in amorphous glassy polymers. application to the investigation of damage-ratcheting interaction in polycarbonate. International Journal of Plasticity, 91:109-133, 2017. https: //doi.org/10.1016/j.ijplas.2016.12.001. 
[5] S. Holopainen, R. Kouhia, N.S. Ottosen, and M. Ristinmaa. Unified lcf-hcf model for motals based on continuum damage mechanics. manuscript, 2017.

[6] S. Holopainen, R. Kouhia, N.S. Ottosen, M. Ristinmaa, and T. Saksala. Modelling of anisotropic high-cycle fatigue. manuscript, 2017.

[7] J. Jussila. Evolution equation based fatigue analysis of a welded structure (in Finnish). Master's thesis, Tampere University of Technology, Department of Mechanical Engineering and Industrial Systems, 2017.

[8] J. Jussila, T. Kaarakka, R. Kouhia, J. Mäkinen, and H. Orelma. Stochastic continuum approach to high-cycle fatigue: modelling stress as Orstein-Uhlenbeck process. manuscript, 2017.

[9] B. Kenmeugne, B.D. Soh Fotsing, G.F. Anago, M. Fogue, J.-L. Roberts, and J.-P. Kenne. On the evolution and comparison of multiaxial fatigue criteria. International Journal of Engineering and Technology, 4(1):37-46, 2012. URL http://www.enggjournals.com/ijet/ docs/IJET12-04-01-015.pdf.

[10] R. Kouhia, S. Holopainen, N.S. Ottosen, M. Ristinmaa, and T. Saksala. A unified LCF-HCF model based on continuum mechanics. In R. Larsson, editor, Proceedings of the 29th Nordic Seminar on Computational Mechanics, 2016. http://www.chalmers.se/en/conference/ nscm29/Pages/default. aspx.

[11] K. Lorand. Review of high-cycle fatigue lodels applied for multiaxial tension-torsion loading based on a new accuracy assesment parameter. Journal of Engineering Studies and Research, 18(3):75-86, 2012.

[12] Y. Murakami. Metal Fatigue, Effects of Small defects and Nonmetallic Inclusions. Elsevier Science, 2002.

[13] N.S. Ottosen, R. Stenström, and M. Ristinmaa. Continuum approach to high-cycle fatigue modeling. International Journal of Fatigue, 30(6):996-1006, June 2008. https//doi .org/ 10.1016/j.ijfatigue.2007.08.009.

[14] N.S. Ottosen, M. Ristinmaa, and R. Kouhia. Continuum approach to high-cycle fatigue modeling - consideration to stress gradients. manuscript, 2017.

[15] I.V. Papadopoulos, P. Davoli, C. Gorla, M. Filippini, and A. Bernasconi. A comparative study of multiaxial high-cycle fatigue criteria for metals. International Journal of Fatigue, 19(3):219-235, 1997. https://doi.org/10.1016/S0142-1123(96)00064-3.

[16] D.F. Socie and G.B. Marquis. Multiaxial Fatigue. Society of Automotive Engineers, Inc., Warrendale, $\mathrm{Pa}, 2000$.

[17] S. Suresh. Fatigue of Materials. Cambridge University Press, 2nd edition, 1998.

Joonas Jussila

AVANT Techno Oy, Ylötie 1, 33470 Ylöjärvi, Finland

joonas. jussila@avanttechno.com

Terhi Kaarakka

Tampere University of Technology, Mathematics, P.O. Box 553, FI-33101 Tampere, Finland

terhi.kaarakka@tut.fi

Sami Holopainen, Reijo Kouhia, Jari Mäkinen, Heikki Orelma, Timo Saksala

Tampere University of Technology, Civil Engineering, P.O. Box 600, FI-33101 Tampere, Finland

sami.holopainen@tut.fi, reijo.kouhia@tut.fi, jari.m.makinen@tut.fi, timo.saksala@tut.fi

Niels Saabye Ottosen, Matti Ristinmaa

Lund University, Solid Mechanics, P.O. Box 118, SE-22100, Sweden

niels_saabye.ottosen@solid.lth.se, matti.ristinmaa@solid.lth.se 